\title{
Where Shall We Draw the Line? Conservatism, Privacy and Digital Modernity \\ Kieron O'Hara
}

\author{
Web and Internet Science Group \\ Electronics and Computer Science \\ University of Southampton \\ Highfield \\ Southampton SO17 1BJ \\ United Kingdom \\ kmoh@soton.ac.uk
}

Presented at the 2018 Amsterdam Privacy Conference, Amsterdam, $6^{\text {th }}$ Oct, 2018

\section{Introduction}

Privacy has usually been the focus of argument within the liberal tradition, as it features at the interface between a number of competing liberal ideals, ranging across the autonomy of the individual, freedom of speech, freedom of association, paternalism, private property, redistribution of wealth, among others. The arguments often cross liberal fault lines, in particular Berlin's well-known distinction between liberty to act, and freedom from harm. For example, privacy drives a wedge between those who believe 'data wants to be free' (Jarvis 2011), and those who believe that, even if that is the wish of the data, data subjects might not share its enthusiasm (Solove 2007). We see arguments about whether, given the complexity of privacy issues, consent is sufficiently sensitive to people's autonomy to ground the data protection regime (Barocas \& Nissenbaum 2009), while other liberals note that, if we scrap consent, plausible replacements are paternalistic without respecting autonomy (Solove 2013). Debate persists about the commercial freedoms of private companies to treat their data as a business asset, in the context of principles such as the third party doctrine (Kerr 2009). Even the concept of data protection itself has inherited this liberal schizophrenia, as its purpose and structure are to balance the privacy interests of individuals with the social interest in the use of data, and the rights of individuals to access information.

Nevertheless, conflicted as it is, liberalism is the chief locus of privacy defence. Privacy is antithetical to the aims of most other ideologies. For instance, communitarians see privacy as a threat to security, a cloak to conceal criminal or subversive behaviour (Etzioni 1999). Feminists see privacy as a protection for spaces in which abuse of women, children and the vulnerable can take place without scrutiny (MacKinnon 1987). Marxists see appropriation, alienation and exploitation while focusing primarily on the legal protections of private spaces and private property (for a specific discussion in the context of social networking, see Ekbia \& Nardi 2017).

In this paper, I wish to explore the possibility that the ideology of conservatism could evolve into a (perhaps unlikely) protector of individual privacy, and could do so without the conflicts characteristic of conservative debate. I will begin by defining conservatism and setting out its goals. Over the following two sections, I will sketch a narrative about how technological change is altering debates about privacy, and finally I will suggest how conservatism is an important lens through which to see 
these changes, and give two examples of approaches, one within the tradition of conservatism and one from the privacy area, that could act as platforms to develop a fully conservative protection of privacy. This argument will not automatically dissolve the tensions in privacy policy, and indeed may usher in new tensions of its own, but the change in viewpoint will, I argue, tilt the balance towards privacy against data, in ways that privacy theorists may find interesting.

One final introductory caveat: I mean by the terms 'liberal' and 'conservative' the ideological concepts that feature in the history of political philosophy, so a liberal is someone in the tradition of, say, John Stuart Mill, who sees liberty as the most important political ideal, and a conservative as someone in the tradition of, say, Edmund Burke, who prefers social stability, continuity, tradition and community to innovation and social engineering. At least since the 1988 US Presidential election, both these terms have been misused in US political discourse in particular, with 'liberal' meaning someone on the left of politics, or even more narrowly, a Democrat, and 'conservative' meaning someone on the right, or even more narrowly, a Republican. This atrocious misuse has even filtered through, regrettably, into academic discourse, with self-identifying 'liberals' and 'conservatives' being tested psychometrically or with big data to produce unsurprising results that have little or no relevance to liberalism or conservatism, or indeed anything else outside of the American political scene (cf. e.g. Jones et al 2018).

\section{The conservative ideology}

Conservatism (O'Hara 2011, Scruton 2017a) is an ideology that problematises change and innovation. This in itself rules out many interpretations that equate 'conservative' with 'right wing', as of course many right-wing politicians or thinkers are either disruptive (e.g. Donald Trump) or keen to promote innovation and 'progress', often through the reduction of restrictions on free markets (e.g. Friedrich Hayek). Neither Trump nor Hayek is conservative in this 'dictionary definition' version of the ideology.

Conservatism is associated with the political right, but this is hardly necessary. One could defend socialist institutions using conservative arguments; supporters of Britain's National Health Service often argue in this way, that the NHS is a national institution whose embedded role in British society precludes attempts to break it up or make it more market-oriented. This highlights an important aspect of conservatism, that it is not, like liberalism, socialism or feminism, an ends-based ideology, but rather is, like nationalism, a situated ideology (Huntington 1957), whose content is different across contexts. If a conservative is worried by change, then depending where she is, she will be concerned to preserve different things. An American conservative will wish to preserve the written constitution, while a British conservative will wish to prevent a constitution being written at all, each taking their current political arrangements as their starting point. A Russian conservative may be nostalgic for Soviet times, while an Iranian conservative will be concerned with ensuring Islamic influences remain in the governance of that country. They may all agree that change is problematic, and for more or less the same reasons, but they will differ dramatically when it comes to the institutions and practices they wish to conserve.

The situated nature of conservatism means that it is not automatically inconsistent with ends-based ideologies, even though all ends-based ideologies necessarily contradict each other (Brennan \& Hamlin 2014). Socialists and liberals may 
sometimes have grounds for forming coalitions, but ultimately they will differ over the ideals governing political action - equality or liberty? But a conservative living in a culture in which there are many functioning socialist institutions and a socialist history will defend those institutions, and one living in a liberal culture will defend the liberties that obtain there. Hence the liberal and the conservative can agree to defend the ancient liberties of a nation like Britain (Burke, a Whig, was seen for many decades after his death as much an apostle of British liberalism as of conservatism), while differing on the ground for the defence. The conservative has no time for the elaborate liberal metaphysics of individual equality, veils of ignorance, and universal rights, and instead argues that, given that liberal institutions have functioned for a long time to sustain a complex society, they clearly have meaning and value within that society, and therefore should be preserved there. They will differ on the desirability of exporting those institutions to other cultures with differing histories. In short, the liberal defends the ancient liberties because they are liberties, while the conservative defends them because they are ancient. A conservative in a liberal society defends liberal practices, norms and regulations, not with the universal principles underlying philosophical accounts of liberalism, but contingently because this is what we do here.

We can see a conservative impulse in many thinkers, ranging from Sextus Empiricus to Montaigne, but we owe the ideology in its current form to the intellectual upheavals of the Enlightenment, when Burke, and other thinkers such as Hume and Smith, pushed back against the optimism of the triumph of reason. The conservative has a strong sense of the imperfection and imperfectability of humankind (Quinton 1978), and is very sceptical about the ability of human society to understand society well enough to innovate within it and engineer its progress (Oakeshott 1991). The Glorious Revolution in Britain in 1688 and the American Revolution in 1776 could each be represented as preserving continuity in those polities, and both are usually treated kindly by conservatives, especially Burke. The French Revolution of 1789-99, however, was a different kettle of fish, deliberately setting out to overthrow the Ancien Régime, and establish a secular, democratic republic along lines suggested by the philosopher Rousseau. Burke's Reflections on the Revolution in France (1790) criticised all its aims, setting out with some prescience the turmoil and slaughter that the Revolution would create.

The French Revolution is a key event in European political history, which helped usher recognisably modern principles into politics, in accord with Enlightenment thinking (Israel 2001), at the expense of what we now think of as pre-modern monarchies and traditional religious cultures. The aim of conservatism, from its genesis, has been to try to hold back the tide of modernity, and protect the premodern. ${ }^{1}$

\section{Privacy from pre-modernity to modernity}

The gradual evolution of the modern world is a narrative placed on history concerned to express or grasp the specificity of the present. The concept emerged in sociology,

\footnotetext{
${ }^{1}$ One caveat: reversing historical progress, such as trying to recreate the Ancien Régime in postrevolutionary France, or recreating 1950s corporate suburban America in today's multicultural society, are just as much social engineering projects as those of rationalist progressives. They should therefore be rejected by consistent conservatives, and conservatism should be seen as distinct from reaction. That is not to say that a conservative cannot be nostalgic and regret the passing of a way of life, only that she cannot hope to engineer its return once it has been destroyed.
} 
and has been influential in political theory and literary/aesthetic theory among other places (Giddens 1990). The narrative is highly general, and its foundation in European and American sociology means it is probably over-reliant on the trajectories of those societies, so that narratives of modernity play out differently in all likelihood in other cultures (Wagner 2012). However, in this paper I will focus on the concepts of modernity that have driven political debate in the rich Western democracies, because these have been the chief loci both of the flourishing of liberalism, and of the debates about privacy alluded to in the Introduction.

\section{The characteristics of modernity}

Broadly speaking, modernity in these cultures stems from two specific ideas that contrast with the pre-modern world, each foregrounded in Enlightenment culture (O'Hara 2010). The first is the autonomy of the individual human being as a knowing subject acting in the world, and the second is the power of reason to understand and predict developments in the world, i.e. the world is intelligible to the knowing subject (Wagner 2012). These two contrast with attitudes in the pre-modern world, in which expectations of communities (which might be expressed as strict social norms, traditions, taboos, or esoteric religious ritual or ceremonies) were often taken as normative, and the world itself was seen as a complex, random set of relationships that could be determined as acts of will by deities, or alternatively as a mysterious given environment that could not be fathomed.

Modernity is a relative term - a society or culture is more modern than something else, which could be another society or an earlier stage of the same society (a) where tradition and geography are stronger influences than rationality and abstraction, (b) which are exclusive rather than inclusive, and (c) where social structures are constraining hierarchies imposed upon populations as opposed to contractual, transactional networks of individuals. The contrast can be therefore in space or time (or both), which indicates that modernity in general, and digital modernity in particular, can be mapped on those two dimensions (Harvey 1990, Koenis 2014, O'Hara 2018).

In the temporal dimension, the important contrast is between backward societies and advanced ones. These two types of society are placed on a single dimension, implying that - if the backward society ceases to reject progress stubbornly - it will eventually evolve to become advanced. Advanced societies have the characteristics of modernity, while in the backward ones one expects, for example, that disputes would be solved by force and by loyalty to clan, not by reason-governed debate, and that governments would be imposed, rather than being chosen by citizens. It is also possible for advanced societies to, as the revealing saying goes, slip back into barbarism, following failure of technology, natural calamity, social unrest or rejection of advanced political wisdom.

In the spatial case, the contrast is between being at the centre of things, and being peripheral (Shils 1975). At the periphery we find rural areas, edgelands and liminal spaces, and the developing world. These contrast with major cities, hubs, centres of excellence, and clusters of creativity and industry where value is added and innovation happens (Formica 2017). Again, these are not incommensurable, so that a peripheral place could become more central with development and trade, and a central place could lose its position through decline, and regain it through regeneration schemes. 


\section{To privacy from obscurity}

The key value of modernity is individuality and the expression of the uniqueness of individuals, as opposed to their social value, their place in a hierarchy or their obedience to and understanding of their social roles. The refinement in the Enlightenment of new sources of authority grounded in human capacities, particularly reason, meant that individuals became more important as political entities, liberty became an ideal, and self-interest, happiness and human nature became part of the toolkit for understanding human behaviour and interaction (O'Hara 2010, 3-12).

This individuality chiefly expressed itself through autonomy and especially choice. Leaders were chosen through democratic processes, and consumption was mediated through newly-theorised free markets. Arranged and dynastic marriages were superseded by romantic love (and if one tired of one's spouse, one could divorce and choose again), and gradually over time one's choices might range over more than just the opposite sex (the artist Tracey Emin has even married a rock). One's choice of career was no longer limited to that of one's father or mother, and - unlike farming, say - career choices were not geographically limiting. One of the chief conceptual innovations of the politics of modernity, the social contract between government and governed, is based upon choice, which is the foundation for any contractual arrangement. In the conditions of modernity, the world presents itself to the individual, who then makes choices from the range it offers.

Where individuality is expressed through choice, privacy becomes a key component. The ideal requires authentic choices by autonomous individuals, and privacy is a vital protector of autonomy (Rössler 2005). Similarly, chosen romantic relationships or deep friendships require intimacy, which in turn demands privacy (Inness 1992). One of the pioneers of Enlightenment thought, John Locke, identified a moral translation away from common dominion, and a turn towards private property, as vital for the development of a free and prosperous society (Locke 1924, 129-141, cf. Habermas 1989). Privacy is therefore baked into the ideals of modernity, which helps explain the admittedly gradual move through the $20^{\text {th }}$ century toward the provision of a legal, regulatory and rights-based framework in such work as (Warren \& Brandeis 1890, Prosser 1960), Article 8 of the European Convention on Human Rights in 1950, and the OECD's data protection principles of 1980.

The pre-modern world had no such requirement for principled privacy protection (although of course people had privacy in many ways). Privacy did not often loom large in pre-modern thought. For example, association was often imposed rather than chosen - marriages were arranged, one's friends were the people one knew in the neighbourhood, and kin relations such as extended families or tribes structured many aspects of interaction and existence. Similarly, decision-making was much less private than in the modern world; practice and tradition were important, and a justification for doing something was often that 'this is what we have always done'. This does not entail that traditions and practices didn't evolve, or novelties appear, only that the evolution was not often marked, and rarely welcomed or sought out. Commands could be issued from arbitrary sources, priests or lords. Prices and wages were often set by tradition rather than market forces. Choosing what to do was the exception rather than the rule. As a third example, archives were often based on memory or arbitrary records; what was recorded depended on who was doing the recording (Krogness 2011). The result was a world in which individuals were not often legible to the state, and therefore hidden, even if in plain sight (Scott 1998). Memory has been long 
superseded by the professionalised, curated archive, where access to information about someone could be controlled by the curator, and facilitated or prevented depending on the rights of the searcher and the rights of the data subject.

Hence, in the pre-modern world, there was little felt need for a principled framework of privacy, whether or not privacy was demanded by individuals (Webb 2007, Vincent 2016). Instead of privacy, the individual had obscurity, with no entitlement to concealment or a private space, but equally the reach of the state or other authorities was relatively feeble and partial. Obscurity was arbitrary, inconsistent and unprotected, and ultimately thought to be unsatisfactory in the modern world (Warren $\&$ Brandeis 1890). New technologies, and the reach of newly-efficient bureaucracies, threatened and ultimately overthrew this obscurity, as portrayed for example in the epic detective work in Dickens' Bleak House (1852-3).

\section{Conservatism and modernity}

Conservatism as we know it, stemming from Burke, was intended to protect the premodern world from the developments of modernity, often using the conceptual resources of the Enlightenment itself, in particular bringing scepticism against authority to bear in the form of reason (O'Hara 2010, 2011). Burke, and later Oakeshott (1991), among others, railed against the ability of rationalists to work out exactly how an innovation would change society, often arguing, not always consistently, that the unintended consequences of change would negate the anticipated benefits of the change itself (Hirschman 1991).

It followed that the whole idea of the social contract was flawed. The fatal disanalogy was that one chooses the conditions to which one will be bound when one signs a contract but one does not choose one's society, family, culture, values, language, religious background or economic, social and educative inheritance. It is impossible to factor these out of any description of, or political mechanism for achieving, the good life for an entire society. The bourgeois revolutionaries failed to speak for large sections of society. The best way to ensure that liberty was catered for in politics was not to try to engineer institutions and outcomes, but rather to observe and preserve the institutions and traditions that had grown up organically within a functioning society. Scrapping these would lead to calamity, as so much social regulation is informal and not rule-based (O'Hara 2010).

Burke's ideas were anticipated by the American revolutionaries, many of whom had conservative instincts. For instance, James Madison, in Federalist Paper no.49 (1788), argued that regular democratic appeals to the people would "deprive the government of that veneration which time bestows on everything, and without which perhaps the wisest and freest governments would not possess the requisite stability.... A reverence for the laws would be sufficiently inculcated by the voice of enlightened reason. But a nation of philosophers is as little to be expected as the philosophical race of kings wished for by Plato" (Madison 1987, 313-314).

Even today, many conservatives either want to defend older, arbitrary, unchosen relationships (Scruton 2017b), or mourn their demise (Scruton 2000), or alternatively to insist on the continued relevance of moral or conceptual schemes that do not compromise with the norms or expectations of a liberal society (Weaver 1948, Kinneging 2009). Many conservatives dislike the idea of legislation to promote or prevent certain behaviour (Oakeshott 1975), and prefer a common law approach to 
holding government to account, providing means for people to coexist in peace (Scruton 2017b, 2017c).

Hence conservatism has usually pitched itself as the defender of the pre-modern. That does not mean that they are opposed to privacy as such; indeed, they are generally unwilling to see the state, whose efforts, however well-meaning, are seen as destructive of civil society, encroach onto the private sphere. Most conservatives defend a private sphere, often but not exclusively seen in economic terms, defended by the state, but within which interference is nobody else's business. Similarly, conservatives value civil society, joint enterprises and social groups formed independently of the state's guidance or oversight. Conservatives also resist deliberate design of social and legal instruments, preferring institutions that evolve organically to permit and accommodate social change (Scruton 2017c).

However, Burke himself was concerned about the potential for the nascent, and what he considered ill-conceived, philosophy of Rousseau, Diderot and Voltaire to cause a collapse in authority, and therefore stability, especially as these ideas became coarsened to extend their populist appeal. He therefore approved of the widespread government surveillance in the revolutionary decade of the 1790s, especially of publishers and authors such as Tom Paine. Since then, conservatives worried by the spread of destabilising ideas have generally supported monitoring those suspected of revolutionary or seditious schemes; Burke was championed anew in the twentieth century by conservatives such as Russell Kirk in the context of the Cold War (Kirk 2009, first published in 1967).

Hence, the development of a principled private sphere designed to maximise autonomous, authentic choice is not on this traditional conservative agenda. Privacy for the conservative is rather a reciprocal type of respect, as with Sherlock Holmes' statement that "we have no excuse for an intrusion upon his privacy until we have some reason to think that there is a guilty reason for it". ${ }^{2}$ Common law defences of privacy fit within the sphere of Burkean conservatism, and so piecemeal privacy protections such as those of the United States are an acceptable approach; a constructed space like the EU data protection regime is far less interesting to the conservative.

To sum up, the traditional Burkean conservative, concerned with defending the premodern against the encroachments of modernity, is not opposed to privacy (unlike, say, a communitarian), but prefers to defend particular existing private spaces and privacy-supportive norms/regulations, and champions the obscurity characteristic of the pre-modern, rather than the constructed private space characteristic of modernity. However, the provision of social stability is one of the chief functions of government, and surveillance in its pursuit is usually justifiable for conservatives.

\footnotetext{
${ }^{2}$ In 'The adventure of the red circle'. In the conversation in which Holmes makes this statement, the mysterious lodger has already been the subject of an invasion of privacy, by virtue of Holmes' discussion of and speculation about his affairs, and an investigation of the contents of his ashtray. Holmes does not assume that it is illegitimate to investigate the lodger without a ground for suspicion, but rather declines to investigate further without an 'excuse'. We can see the modern idea of a principled private space beginning to emerge from Holmes' remark, but it is not yet in place. The only cause for suspicion about the lodger at this point in the story is, in fact, his desire for greater privacy from his landlady than is usual in a lodger/landlady relationship.
} 


\section{Digital modernity and the decline of privacy}

Modernity is perpetually evolving, and takes on new forms depending on social contexts (Wagner 2012). One key technological development that has affected modernity's evolution is the ubiquity of digitally-connected networks across society. Elsewhere, I have described this as digital modernity (O'Hara 2018). We might contrast this with the modernity under discussion above, which to distinguish it we could now term analogue modernity.

Digital modernity, like analogue modernity, is essentially a narrative, even a myth, about the present and its relation to the future. The myth, popular across the political spectrum, says that digital technology is irrevocably shaping our future in a rich set of significant ways; it is our destiny, and a highly desirable one at that (Kurzweil 2005, Mason 2013, Schmidt \& Cohen 2013, Brynjolfsson \& Andrew McAfee 2014, Barrat 2015, Schwab 2016). The narrative might be descriptive, or teleological, or normative, but by virtue of being common currency across policymakers, commentators and businesspeople, it is becoming self-fulfilling. Its truth, in this sense, is neither here nor there.

Digital modernity, though in many ways distinct from its analogue predecessor, is still a species of modernity. The chief value it espouses remains that of individuality, and the individual keeps a central role. However, the means of expression of individuality is different. Rather than being, as in analogue modernity, the choices made by autonomous individuals, in digital modernity individuality's expression is through personalisation. Instead of a world presented to an individual to select the aspects he or she prefers, digital modernity contracts to use the data generated by uncountably many transactions to mould the world around the individual's preferences (cf. e.g. Negroponte 1995, Speretta \& Gauch 2005, Qiu \& Cho 2006, Guy et al 2010, Ricci et al 2011, Masthoff et al 2014, Agrawal et al 2018, Hamari et al 2018).

Digital modernity consists, we might say, of a shift in tense. The pre-modern world was eternal - traditions and institutions were conceived as changeless (even though they weren't). Analogue modernity put the emphasis firmly on the present: the individual chooses what he or she wants at this particular moment, so that, as the modernising pioneer Henry Ford said, history is bunk. Digital modernity is made up of systems which can 'read' the state of the digital avatar, and then provide the goods that the individual would have chosen if he or she possessed total knowledge about choices and happiness; it therefore shifts tense to the subjunctive. Personalisation is developed on the basis of past choices (both of the individual and of others classified as similar), and on correlations between choices and outcomes, to try to 'nudge' the individual into making the rational choices that take into account long term goals as well as short term gratification (Thaler \& Sunstein 2008).

\section{Digital modernity in time and space}

Modernity shrinks time and space (Harvey 1990), and digital modernity accelerates these trends (O'Hara 2018). On the temporal dimension, it is the nature of digital technology to disintermediate and disrupt existing processes (Curley \& Salmelin 2018, 15-25), and this is where technologists look to create innovation (Christensen et al 2015, Yang et al 2016). The ability of the advanced society to innovate at will is one of the things that distinguish it from the backward one, and a highly advanced society would be expected to innovate routinely. Since innovation is disruptive, the super-advanced society will be super-disruptive, a world of startups where disruption 
is routine, and where institutions and entrepreneurs would be expected to adapt constantly to new pressures; Schumpeter's (1950) concept of creative destruction will predominate. Taken to the extreme, this is a world in which to be advanced is to be a disruptor, and therefore it follows immediately that to exist is to be backward. Once a system is implemented, or a product produced, it is ripe for disruption from radical innovators (Colombo et al 2015).

On the spatial dimension, modernisation marginalises the periphery and privileges the centre. An innovation cluster is tightly-packed, and acquaintance is not rationed by geography, and so we can develop many more links with others, creating richer networks. Digital modernity extends this logic to produce the idea of cyberspace, a compression of space via quantification to produce greater intelligence (O'Hara 2018), famously described in William Gibson's novel Neuromancer.

Cyberspace. A consensual hallucination experienced daily by billions of legitimate operators, in every nation, by children being taught mathematical concepts. ... A graphic representation of data abstracted from the banks of every computer in the human system. Unthinkable complexity. Lines of light ranged in the nonspace of the mind, clusters and constellations of data. Like city lights, receding ... (Gibson 1984, 69)

Rational connection is increasingly the norm, because data is searchable and we can find the connections we want, rather than be satisfied with those that are available. Cyberspace is populated by avatars, digital doubles or digitally-extended selves, made up of increasingly rich data (Parkinson et al 2017). The quantified self movement positions self-tracking sensors as interfaces for improving technological engagement, and our lives become as a result more data-driven (Ruckenstein \& Pantzar 2017). Smart cities are a response to the technical, material, social and organisational problems associated with modernity and urban growth, to improve quality of life and provide a competitive and sustainable city (Shapiro 2006, Batty et al 2012). The Internet of Things will accelerate these trends further (Zanella et al 2014). Policy depends now on the state of the person's data, not of the flesh and blood human. Hence cyberspace affords opportunities for order and rationality, and the best that hapless reality can achieve is to get closer to the perfection of the algorithm and the data.

\section{Privacy in the subjunctive world}

As we have seen, privacy occupies a key place in the infrastructure of modernity. With digital modernity, however, not only does privacy lose its pivotal position, it becomes a hindrance, because the provision of personalised services is only possible to the extent that the individual is transparent to the provider (Chellappa \& Sin 2005, Golbeck 2016). On this revised narrative, privacy is not only not a route to the expression of individuality - it stands in its way.

One of the reasons for this is the way that networked digital technologies have evolved to generate extraordinary amounts of data. Another, however, follows from the logic of choice as an expression of individuality - in other words, the defining trope of analogue modernity. The choices available to an individual depend on what providers or markets are prepared to serve up - recall another of Ford's aphorisms about the Model-T, that the customer could have any colour he liked as long as it was black. As people accelerated the choices they made, to create the consumerist society of the late $20^{\text {th }}$ century, the range of choices provided by mass production began to 
widen to cater for this demand. At some point, choices become so fine-grained that the number of possibilities to choose from becomes unmanageable, and the consumer or citizen is forced to rely on recommendations. A desideratum of the recommendation is that it differentiates the consumer (rather than recommending the same popular blockbuster choices to everybody), and therefore the recommendation system needs to know about the individual, to infer what he or she would have chosen. Analogue modernity contained within itself the seeds of the governing principle of digital modernity, even in advance of the extraordinary development of the technology.

If we reconsider association, decision-making and archiving, the three sample vectors of privacy whose evolution from pre-modernity to modernity is described above, we see exemplars of how this plays out in the transition to digital modernity from analogue modernity. Technology has created a world in which choices about association are mediated by recommender systems. Apps are now routinely used to suggest people to date, to marry, to go to bed with, to befriend, to employ, or who will be valuable for our careers. In decision-making, the moulding of our preferences is increasingly overt. Messages and advertisements are tailored for consumers' or citizens' personal circumstances, and decisions are 'nudged'. The world is crafted so that the choices citizens or consumers should want to make are anticipated and made apparent to them, while those they may regret are hidden. The risk and effort of choice is reduced. Thirdly, the curated archives with access controls and special purpose representation languages characteristic of analogue modernity are increasingly being superseded under digital modernity by large-scale, open, searchable information spaces, whose data is relatively straightforward to discover and increasingly straightforward to link to data from other sources. Google and other search engines have democratised search, and are becoming more sophisticated in matching the searcher with the documents or information that will satisfy their queries.

Digital modernity subtly undermines some aspects of privacy in other ways as well. For example, the ability to disintermediate complex processes reduces the grain size of people's choices. The (somewhat misnamed) sharing economy, for example, relies on maximising use of assets and allowing consumers to pay only for what they use (transport, accommodation, small quantities of others' labour, land for agriculture or gardening, and so on) when the asset would otherwise be idle. This has the effect of reducing the amount of private property that a person would typically need to secure in order to have the same level of service.

Indeed, with blockchain technology, some have even theorised that private property itself might be seriously disrupted, because the peer-to-peer network could manage the connection between user and asset using blockchains, smart contracts and cryptocurrencies. The Fairbike scheme proposes a DAO (Decentralised Autonomous Organisation) for bicycle-sharing in which "each bike collects its own money and reinvests these funds back into the network by issuing repairs or if the situation allows it, expand the service by adding a new bicycle to the network" (https://the-incrediblemachine.com/fairbike.html). The bicycles themselves form an autonomic or autopoietic system which will maintain and reproduce itself, while each bicycle would in effect own itself.

It is, on the other hand, fair to say that some applications of blockchain also increase privacy, most obviously by making financial transactions more anonymous than 
electronic banking would facilitate, if not quite as anonymous as (pre-modern) cash. With blockchain, the ability to maintain ledgers via a peer-to-peer network can be disruptive of the centralised neatness of analogue modernity, while increasing the speed and rationality of public recording. But in particular, blockchain interferes with the principled private spaces characteristic of modernity defined and regulated by law. The privacy afforded by blockchains depends on which systems get built, with what functions, and who is prepared to take the risks of using them. In this way, privacy becomes less of a defined space and more of a market, as approved, for example, by Posner (1983), and see also (Posner \& Weyl 2018), which talks of technology uprooting capitalism and democracy, using data to undermine the principle of private property, replacing the 'monopoly' of property with technologically-facilitated public auctions for public benefit. The result is a retreat from the principled private spaces of analogue modernity, and a move back towards the arbitrary obscurity that characterised the pre-modern.

\section{Conservatism and digital modernity}

With its focus on the protection of traditions and institutions against the tide of modernity, conservatism's ambivalence toward privacy, and support for the arbitrary obscurity of pre-modernity is explicable. However, the advances of the modern world have been major and permanent, and protests against them look increasingly Quixotic. More to the point, the conservative's respect for the private domain (however arbitrarily drawn) may be better asserted against the increasingly powerful state, large corporations and overweening technology through the use of principled regulation, in the modern style, rather than relying on contingent and arbitrary practices.

Does conservatism have the intellectual resources to do this? Recall that it is a situational ideology - what it supports and condemns depends largely on what is already in place and what functions within a society. Many social practices, norms and expectations have built up around, or adapted to, the institutions of modernity, and it is perfectly consistent for a conservative to try to conserve these, many of which (including data protection law) have stood the test of time. In short, the conservative, instead of defending the pre-modern against the modern, could defend the modern against the digitally modern, if there is sufficient value created and sustained by modern institutions. She would use the same types of argument that animated Burke, while accepting that the passage of time and social evolution means that she cannot draw the line in the same place as he did.

Such a conservative would then be drawn to defend the principled private space that is required by analogue modernity in those cultures where modernity has stood the test of time - certainly the wealthy democracies - though she will find it hard to export the argument to, say, an illiberal democracy such as Singapore, or those countries where digital modernity serves more narrowly-defined, perhaps nationalistic purposes, such as China. Her defence of privacy would be culturally-sensitive, unlike those of liberal thinkers, but correspondingly less able to support more universal arguments about, for example, the nature of the Internet and its governance.

In this section, I argue that there are resources available to the privacy-sensitive conservative prepared to defend the principles of analogue modernity in the digitally modern world, first giving an example of a conservative thinker who did defend modernity, and secondly looking at a conservative-friendly privacy argument. 


\section{A conservative defence of modernity}

Michael Oakeshott is a complex philosopher to characterise. His political writings are deliberately abstract, and he downplayed apparent connections between philosophical writings (either his own or other people's) and the day-to-day ideological engagement with quotidian politics. Much of his work defends liberty, both in terms of the freedom of the individual to pursue his own idea of what is good, and in terms of freedom of association and the importance of private associations and enterprises as the underpinnings of civil society. As a result, many commentators classify him as a liberal, or even an anarchist. However, his resistance to the involvement of the state in civil societies, to abstract accounts of the individual or of society, and to rationalist attempts at social engineering and innovation have prompted others (including O'Hara 2011) to include him in the conservative camp. For a review of Oakeshott's work and of these complex issues of classification, with a full set of references, see (Podoksik 2003).

Oakeshott certainly accepted and described many of the phenomena of modernity in his work. His principal focus was on the irreducible plurality of life under modernity, a theme developed in his earliest book (Oakeshott 1933), in which he argued that methods of experiencing and understanding the world collected under particular projects or disciplines, such as science, art or religion, were, in their purest form at least, worlds of their own and representations of a totality, and therefore independent of each other. The imperfection of human understanding means that these modes, as he called them, could never be completely understood, and so the scientist, the philosopher, the historian, the poet or the social scientist could never transcend their boundaries.

Hence Oakeshott rejected hierarchical pre-modern views which privileged a particular perspective, such as Christianity, positivism, or ideas such as philosophy being the 'queen of the sciences'. He embraced a radical plurality that rejected the idea of points of contact between the different modes. Science and poetry, say, are simply different things for Oakeshott, and their methods and truths remain autonomous. In this, he followed a number of European philosophers and sociologists, including Nietzsche, Simmel and Collingwood. However, whereas they were often pessimistic about this pluralism, regarding it as a tragedy, Oakeshott welcomed and defended it. Indeed, he was clear that each mode was in itself a valuable tradition which was worth defending.

In this paper, I have characterised modernity first and foremost as an attitude toward individuality. Oakeshott also theorised about the self-contained nature of the individual, and was particularly critical in (Oakeshott 1975) about individuals who failed to express their individuality, and who relied on external direction to give their lives meaning. Such individuals manqués were self-alienated and threats to a wellfunctioning plural society.

It is usually argued that this combination of views renders Oakeshott's status as a conservative problematic (Podoksik 2003), because of his defence modernity against pre-modern traditions. However, conservatism is always relative to what the conservative defends or wishes to conserve, and Oakeshott's opposition to the premodern stems from his conviction that that phase of history has passed, and any attempt to re-establish it will simply be unconservative reaction - not preserving anything, but a type of social engineering, and furthermore an attempt to reduce the hard-won liberty of the individual. Oakeshott is not simply a relativist, but rather a 
pluralist; he actively defends modern pluralism as a collection of valuable traditions in their own right against the radical deconstructions of post-modernism.

Oakeshott's conservatism is akin to Burke's, both defending liberal societies against radical innovators. However, the actual liberal entities they defend are different, because of their different standpoints, Burke resisting the French revolutionaries, and Oakeshott writing in the Cold War. Oakeshott does not discuss privacy systematically, although he covers some aspects of it, including private associations and the need for freedom from encroachment from the state or from social engineers. He did not write very much about technology, and an Oakeshottian commentary on digital modernity would have to do some reconstruction; nevertheless, some lines can be discerned. For example, the $21^{\text {st }}$ century conservative might ask herself whether the individual of digital modernity for whom the world is personalised is a genuine individual, in Oakeshott's terms, or rather an individual manqué, passively responding to technology's recommendations. She might also consider whether the totalising epistemological claims of science, and particularly data science, are defensible against conservative scepticism about rationalism (Oakeshott 1991). Most importantly, she would have to think about what a principled private space should look like in the context of a conservative philosophy.

\section{A conservative defence of privacy}

Defences of privacy tend to be based on abstract theorising about the value of privacy to individuals using liberal principles. A more congenial argument for a conservative thinker would be an argument based on the practices of settled communities legible to their members, respecting the importance of such practices for supporting, sustaining and reproducing what individuals within such communities find valuable. Even for relatively mobile individuals in a globalised age, the importance of settled communities to support their transactional relationships is a key assumption of conservatism (Scruton 2017c).

To that end, it would be helpful to find defences of privacy along these lines. One such is Nissenbaum's theory of contextual integrity (2010). Nissenbaum moves away from abstract ideas of data protection and control over personal data, and argues that trying to define the limits of public and private space is a mistake, and that information should rather be distributed and processed according to the norms appropriate for particular social contexts, such as family, work, healthcare, education, finance and so on. The important thing to conserve is the existing fabric of social life, and digital technology should be taken as problematic only (or especially) when it abstracts away from this context, so that the context itself loses its integrity and is threatened by new technologies creating novel privacy-threatening practices.

I have argued above that the narrative of digital modernity will inevitably threaten privacy, and so contextual integrity. Nissenbaum's argument makes no essential reference to anti-conservative principles, and indeed is highly sympathetic to conservative concerns about the preservation of existing practices and patterns of behaviour. Many privacy scholars, however, see this as a downside of her theory (e.g. Debatin 2011).

Nissenbaum does discuss the relationship of contextual integrity to conservatism (2010, 159-165), arguing that we need "systematic criteria to measure the moral standing of established practice against challengers to justify when the latter should be accepted or resisted" $(2010,164)$, to give her theory appropriate moral standing. She 
appears somewhat embarrassed by the conservative implications of her work, worrying about 'the tyranny of the normal' (conservatives generally being rather fond of the normal). Others are similarly worried; for example (Grodzinsky \& Tavani 2010) argue that a conservative stance on contextual integrity must be 'relegated' to a descriptive theory. Here stands the research question for a conservative gearing up to defend privacy: does she need such criteria, and if she does, can they be made properly conservative? Clearly, the criteria could be framed in such a way as to prevent the contextual integrity theory being conservative. The bar could be set in terms of social gain measured economically (and so producing a free-market neoliberal view), or the defence of particular class interests (a socialist theory), or the criteria may rest on a rationalist understanding of social engineering, so challenging conservative epistemological scepticism.

In any case, in a conservative world-view, the mere existence over time of social practices is a (defeasible) reason to value them, and so it may be that no such criteria, at least not systematic ones, are necessary from a conservative point of view. Contextual integrity is a theory that has commanded a great deal of respect in the privacy field, but whose ideological underpinnings seem distinct from those of liberalism, and more akin to conservatism. Although Nissenbaum and others have worked to find additions to the theory that would 'cure' it of the conservative virus, there is no reason to think that conservatism should not take on this kind of respect for existing institutions and use it to defend privacy in the context of digital innovation.

\section{Conclusion}

I have argued that privacy evolved from obscurity during the long transition from premodernity to modernity, and that digital modernity now threatens the principled private space that modernity requires. Liberalism is the ideology that most enthusiastically embraced (and shaped) modernity and digital modernity alike, and so is now somewhat conflicted with respect to privacy. It may be that the unfashionable ideology of conservatism is better placed to defend privacy, if conservatives shift their focus from the defence of pre-modern tradition, to the defence of those wellestablished practices and institutions characteristic of analogue modernity. This is possible, as we have seen with the work of Michael Oakeshott. Furthermore, privacy can be defended from beyond the liberal position, as we have seen with the work of Helen Nissenbaum. There is still considerable work to join the dots and to create a genuinely privacy-friendly conservative philosophy, but this paper has argued that the resources are there for this work to begin.

\section{References}

Ajay Agrawal, Joshua Gans \& Avi Goldfarb (2018). Prediction Machines: The Simple Economics of Artificial Intelligence, Boston: Harvard Business School Press.

Solon Barocas \& Helen Nissenbaum (2009). 'On notice: the trouble with notice and consent', in Proceedings of the Engaging Data Forum: The First International Forum on the Application and Management of Personal Electronic Information, https://papers.ssrn.com/sol3/papers.cfm?abstract_id=2567409.

James Barrat (2015). Our Final Invention: Artificial Intelligence and the End of the Human Era, New York: Thomas Dunne Books. 
M. Batty, K.W. Axhausen, F. Giannotti, A. Pozdnoukhov, A. Bazzani, M. Wachowicz, G. Ouzounis \& Y. Portugali (2012). 'Smart cities of the future', European Physical Journal Special Topics, 214(1), 481-518.

Geoffrey Brennan \& Alan Hamlin (2014). 'Comprehending conservatism: frameworks and analysis', Journal of Political Ideologies, 19(2), 227-239.

Erik Brynjolfsson \& Andrew McAfee (2014). The Second Machine Age: Work, Progress and Prosperity in a Time of Brilliant Technologies, New York: W.W. Norton.

Ramnath K. Chellappa \& Raymond G. Sin (2005). 'Personalization versus privacy: an empirical examination of the online consumer's dilemma', Information Technology and Management, 6(2-3), 181-202, https://doi.org/10.1007/s10799-005-5879-y.

Clayton M. Christensen, Michael E. Raynor \& Rory McDonald (2015). 'What is disruptive innovation?' Harvard Business Review, https://hbr.org/2015/12/what-isdisruptive-innovation.

Massimo Colombo, Chiara Franzoni \& Reinhilde Veugelers (2015). 'Going radical: producing and transferring disruptive innovation', Journal of Technology Transfer, 40(4), 663-669.

Martin Curley \& Bror Salmelin (2018). Open Innovation 2.0: The New Mode of Digital Innovation for Prosperity and Sustainability, Cham: Springer.

Bernhard Debatin (2011). 'Ethics, privacy, and self-restraint in social networking', in Sabine Trepte \& Leonard Reinecke (eds.), Privacy Online: Perspectives on Privacy and Self-Disclosure in the Social Web, Berlin: Springer, 47-60.

Hamid R. Ekbia \& Bonnie A. Nardi (2017). Heteromation: and Other Stories of Computing and Capitalism, Cambridge MA: M.I.T. Press.

Amitai Etzioni (1999). The Limits of Privacy, New York: Basic Books.

Piero Formica (ed.) (2017). Entrepreneurial Renaissance: Cities Striving Towards an Era of Rebirth and Revival, Cham: Springer.

William Gibson (1984). Neuromancer, New York: Ace Books.

Anthony Giddens (1990). The Consequences of Modernity, Cambridge: Polity Press.

Jennifer Golbeck (2016). 'User privacy concerns with common data used in recommender systems', in Emma Spiro \&Yong-Yeol Ahn (eds.), Social Informatics: Proceedings of the $8^{\text {th }}$ International Conference, SocInfo 2016, Cham: Springer, 468480, https://doi.org/10.1007/978-3-319-47880-7_29.

Frances Grodzinsky \& Herman T. Tavani (2010). 'Applying the "contextual integrity" model of privacy to personal blogs in the blogosphere', International Journal of Internet Research Ethics, 3(1), 38-47.

Ido Guy, Naama Zwerdling, Inbal Ronen, David Carmel \& Erel Uziel (2010). 'Social media recommendation based on people and tags', in Proceedings of the $33^{\text {rd }}$ International ACM SIGIR Conference on Research and Development in Information Retrieval, New York: ACM, 194-201, https://doi.org/10.1145/1835449.1835484.

Jürgen Habermas (1989). The Structural Transformation of the Public Sphere: An Inquiry Into a Category of Bourgeois Society, Cambridge: Polity Press. 
Juho Hamari, Lobna Hassan \& Antonio Dias (2018). 'Gamification, quantified-self or social networking? Matching users' goals with motivational technology', User Modeling and User-Adapted Interaction, 28(1), 35-74, https://doi.org/10.1007/s11257-018-9200-2.

David Harvey (1990). The Condition of Postmodernity: An Enquiry Into the Origins of Social Change, Oxford: Blackwell.

Albert O. Hirschman (1991). The Rhetoric of Reaction: Perversity, Futility, Jeopardy, Cambridge MA: Harvard University Press.

Samuel P. Huntington (1957). 'Conservatism as an ideology', American Political Science Review, 51(2), 454-473, https://doi.org/10.2307/1952202.

Julie Inness (1992). Privacy, Intimacy and Isolation, New York: Oxford University Press.

Jonathan I. Israel (2001). Radical Enlightenment: Philosophy and the Making of Modernity 1650-1750, Oxford: Oxford University Press.

Jeff Jarvis (2011). Public Parts: How Sharing in the Digital Age Improves the Way We Work and Live, New York: Simon \& Schuster.

Kevin L. Jones, Sharareh Noorbaloochi, John T. Jost, Richard Bonneau, Jonathan Nagler \& Joshua A. Tucker (2018). 'Liberal and conservative values: what we can learn from Congressional tweets', Political Psychology, 39(2), 423-443, https://doi.org/10.1111/pops.12415.

Orin S. Kerr (2009). 'The case for the third-party doctrine', Michigan Law Review, 107(4), 561-602.

Andreas Kinneging (2009). The Geography of Good and Evil: Philosophical Investigations, Wilmington DE: ISI Books.

Russell Kirk (2009). Edmund Burke: A Genius Reconsidered, $2^{\text {nd }}$ revised edition, New York: ISI.

Sjaak Koenis (2014). Voices of the People: Pluralism in Dutch Politics (1994-2014), Amsterdam: VU University Press.

Karl Jakob Krogness (2011). 'Numbered individuals, digital traditions, and individual rights: civil status registration in Denmark 1645 to 2010', Ritsumeikan Law Review, 28, http://www.ritsumei.ac.jp/acd/cg/law/lex/rlr28/KROGNESS.pdf.

Ray Kurzweil (2005). The Singularity is Near, New York: Viking Penguin.

John Locke (1924). 'An essay concerning the true original extent and end of civil government', in John Locke, Two Treatises of Government, London: Everyman, 117242.

Catherine A. MacKinnon (1987). 'Privacy v. equality: beyond Roe v. Wade', in Catherine A, MacKinnon, Feminism Unmodified: Discourses on Life and Law, Cambridge MA: Harvard University Press, 93-102.

James Madison (1987). 'No.49: the same subject continued with the same view', in James Madison, Alexander Hamilton \& John Jay, The Federalist Papers, London: Penguin, 312-316.

Paul Mason (2013). Why It's Still Kicking Off Everywhere, London: Verso. 
Judith Masthoff, Floriana Grasso \& Jaap Ham (2014). 'Preface to the special issue on personalization and behavior change', User Modeling and User-Adapted Interaction, 24(5), 345-350, https://doi.org/10.1007/s11257-014-9151-1.

Nicholas Negroponte (1995). Being Digital, New York: Alfred A. Knopf.

Helen Nissenbaum (2010). Privacy in Context: Technology, Policy and the Integrity of Social Life, Stanford: Stanford University Press.

Michael Oakeshott (1933). Experience and its Modes, Cambridge: Cambridge University Press.

Michael Oakeshott (1975). On Human Conduct, Oxford: Clarendon Press.

Michael Oakeshott (1991). 'Rationalism in politics', in Michael Oakeshott, Rationalism in Politics and Other Essays, Indianapolis: Liberty Fund, 5-42.

Kieron O'Hara (2010). The Enlightenment: A Beginner's Guide, Oxford: Oneworld.

Kieron O'Hara (2011). Conservatism, London: Reaktion Books.

Kieron O'Hara (2018). 'The contradictions of digital modernity', AI and Society, https://doi.org/10.1007/s00146-018-0843-7.

Brian Parkinson, David E. Millard, Kieron O'Hara \& Richard Giordano (2017). 'The digitally extended self: a lexicological analysis of personal data', Journal of Information Science, 44(4), 552-565, https://doi.org/10.1177/0165551517706233.

Efraim Podoksik (2003). In Defence of Modernity: Vision and Philosophy in Michael Oakeshott, Exeter: Imprint Academic.

Eric A. Posner \& E. Glen Weyl (2018). Radical Markets: Uprooting Capitalism and Democracy for a Just Society, Princeton: Princeton University Press.

Richard A. Posner (1983). The Economics of Justice, Cambridge MA: Harvard University Press.

William L. Prosser (1960). 'Privacy', California Law Review, 48, 383-423.

Feng Qiu \& Junghoo Cho (2006). 'Automatic identification of user interest for personalized search', in Proceedings of the $15^{\text {th }}$ International Conference on the World Wide Web, New York: ACM, 727-736, https://doi.org/10.1145/1135777.1135883.

Anthony Quinton (1978). The Politics of Imperfection: The Religious and Secular Traditions of Conservative Thought in England From Hooker to Oakeshott, London: Faber \& Faber.

Francesco Ricci, Lior Rokach \& Bracha Shapira (2011). 'Introduction to Recommender Systems Handbook', in Francesco Ricci, Lior Rokach, Bracha Shapira \& Paul B. Kantor (eds.), Recommender Systems Handbook, Boston: Springer, 1-35, https://doi.org/10.1007/978-0-387-85820-3_1.

Beate Rössler (2005). The Value of Privacy, Cambridge: Polity Press.

Minna Ruckenstein \& Mika Pantzar (2017). 'Beyond the quantified self: thematic exploration of a dataistic paradigm', New Media and Society, 19(3), 401-418.

Eric Schmidt \& Jared Cohen (2013). The New Digital Age: Reshaping the Future of People, Nations and Business, New York: Random House. 
Joseph Schumpeter (1950). Capitalism, Socialism and Democracy, $3^{\text {rd }}$ edition, New York: Harper \& Row.

Klaus Schwab (2016). The Fourth Industrial Revolution, Geneva: World Economic Forum.

James C. Scott (1998). Seeing Like a State: How Certain Schemes to Improve the Human Condition Have Failed, New Haven: Yale University Press.

Roger Scruton (2000). England: An Elegy, London: Chatto \& Windus.

Roger Scruton (2017a). Conservatism: An Invitation to the Great Tradition, New York: All Points Books.

Roger Scruton (2017b). On Human Nature, Princeton: Princeton University Press.

Roger Scruton (2017c). Where We Are: The State of Britain Now, London: Bloomsbury.

Jesse M. Shapiro (2006). 'Smart cities: quality of life, productivity and the growth effects of human capital', Review of Economics and Statistics, 88(2), 324-335.

Edward Shils (1975). Center and Perphery: Essays in Macrosociology, Chicago: University of Chicago Press.

Daniel J. Solove (2007). The Future of Reputation: Gossip, Rumor and Privacy on the Internet, New Haven: Yale University Press.

Daniel J. Solove (2013). 'Privacy self-management and the consent dilemma', Harvard Law Review, 126(7), 1880-1903.

Micro Speretta \& Susan Gauch (2005). 'Personalized search based on user search histories', in Proceedings of the 2005 IEEE/WIC/ACM International Conference on Web Intelligence, New York: ACM, 622-628, https://doi.org/10.1109/WI.2005.114.

Richard H. Thaler \& Cass R. Sunstein (2008). Nudge: Improving Decisions About Health, Wealth and Happiness, New Haven: Yale University Press.

David Vincent (2016). Privacy: A Short History, Cambridge: Polity Press.

Peter Wagner (2012). Modernity: Understanding the Present, Cambridge: Polity Press.

Samuel D. Warren \& Louis D. Brandeis (1890). 'The right to privacy', Harvard Law Review, 4, 193-220.

Richard M. Weaver (1948). Ideas Have Consequences, Chicago: University of Chicago Press.

Diana Webb (2007). Privacy and Solitude, London: Hambledon Continuum.

Yi Yang, Wencui Han \& Michael Shaw (2016). 'A framework for disruptive innovation diffusion', in Proceedings of Adoption and Diffusion of Information Technology (SIGADIT), http://aisel.aisnet.org/amcis2016/Adoption/Presentations/4/.

Andrea Zanella, Nicola Bui, Angelo Castellani, Lorenzo Vangelista \& Michele Zorzi (2014). 'Internet of Things for smart cities', IEEE Internet of Things, 1(1), 22-32. 